\title{
Reflectie over het onderwijs en het NVMO-congres 2004
}

\author{
A.J.J.A. Scherpbier
}

\section{Samenvatting}

Het visitatierapport en het NVMO-congres in 2004 inspireerden tot reflectie over aandachtspunten in het medisch onderwijs.

Visitatierapport: De opleidingen verschillen minder. De jaarlijkse Elsevier-enquête bevestigt dit. De effecten van de universitaire medische centra en de curriculumherzieningen zullen nog moeten blijken. De stijgende studentenaantallen vereisen meer gekwalificeerde docenten om kwaliteit te waarborgen, vooral in het patiëntgebonden onderwijs, waar student-patiëntcontacten zelden geobserveerd worden. Om rendementen te verbeteren zijn duidelijke examenreglementen, opsporing van probleemstudenten en voorkomen van wachttijden belangrijk. Sinds de oprichting van onderwijsinstituten wordt onderwijs professioneler benaderd. Valkuilen hierbij zijn: bureaucratisering, te weinig ruimte voor echte 'opleiders' en te weinig zelfkritiek en reflectie. Dit benadrukt de noodzaak van kritische externe visitaties, mede gezien het onvoldoende functioneren van interne kwaliteitszorgsystemen. Andere verbeterpunten zijn aandacht voor wetenschappelijke en academische vorming, toetsing en beoordeling, en internationalisering.

NVMO-congres: Op het congres wordt benadrukt dat de Nederlandse Vereniging voor Medisch Onderwijs (NVMO) veel belang hecht aan samenwerking met het Centraal College Medische Specialismen (CCMS). Aandacht voor professionalisering blijkt uit het toegenomen aantal workshops. Met strengere selectie van papers wordt kwaliteitsverbetering van presentaties beoogd. Het schrijven van artikelen wordt gestimuleerd, omdat artikelen een groter publiek bereiken dan congrespresentaties. Verheugend is dat Nederland tussen 1995 en 2004 steeg van plaats vijf naar plaats drie op een lijst van landen met publicaties in internationale medisch-onderwijstijdschriften.

Hoe verder: Onderwijsverbeteringen vragen een kritische houding van faculteiten en bestuurders. Een combinatie van interne en externe kwaliteitszorg met kritische externe commissies kan dit stimuleren. In het onderzoek moeten - na veel aandacht voor ontwikkelwerk - nu de echte effecten centraal staan. (Scherpbier AJJA. Reflectie over het onderwijs en het NVMO-congres 2004. Tijdschrift voor Medisch Onderwijs 2005;24(5):197-203.)

\section{Inleiding}

In 2004 verscheen het rapport van de Visitatiecommissie Geneeskunde. ${ }^{1}$ De commissie constateert dat de grote verschillen in opleidingskwaliteit die de vorige commissie aantrof veel kleiner geworden zijn: "de pieken en ravijnen van 1997 zijn veranderd in een heuvellandschap" ${ }^{1}$ Deze bevinding komt overeen met een overzicht van de resultaten van de Elsevier-enquêtes van 1994-2004. De commissie heeft gelukkig ook kritiek. Ze heeft helemaal gelijk: het is echt niet allemaal 'rozengeur en maneschijn' in het medisch onderwijs. Wie verder durft te kijken dan de lokale pr-praatjes en durft te reflecteren ontdekt nog wel 'het een en ander' dat beter kan. In dit artikel wordt ingegaan op mogelijke verbeteringen op basis van de adviezen van de visitatiecommissie en de resulta- 
ten van de Elsevier-enquête. Ook wordt nagegaan hoe we er internationaal voor staan. In 2004 was er ook het veertiende NVMO-congres, met als hoofdorganisator Anselm Derese uit Gent. Hoe verliep het congres? Hoe was de kwaliteit? Wat kon beter? Deze vragen komen ook aan bod in dit artikel. Tot slot zal een blik in de toekomst worden geworpen.

\section{De visitatie geneeskunde}

Twee leden van de commissie hebben eerder in dit tijdschrift gerapporteerd over onderdelen van de visitatie. ${ }^{2}$ In het onderstaande wordt ingegaan op de algemene bevindingen uit het rapport. ${ }^{1}$ Er zijn grote veranderingen geweest in medisch onderwijsland sinds de vorige visitatie. In de meeste faculteiten is een universitair medisch centrum (UMC) gevormd. Het is interessant om de komende jaren te zien wat het effect voor het onderwijs hiervan is. Vrijwel alle curricula zijn ingrijpend veranderd. Op papier zijn het mooie plannen. Wat het betekent voor het 'curriculum in actie' zal nog moeten blijken. De meest dramatische verandering is de snelle toename van de aantallen studenten. De commissie constateert: "handhaving laat staan verbetering van de kwaliteit van het medisch onderwijs bij de toenemende instroom van studenten is niet mogelijk zonder uitbreiding van het aantal gekwalificeerde docenten en begeleiders" ${ }^{1}$ Voor het beoordelen van de effecten van deze veranderingen was de visitatie te vroeg. Reflectie, maar ook onderzoek naar het curriculum in actie, is de komende jaren dus van belang. De toename van de aantallen studenten is vooral riskant voor de patiëntgebonden onderwijsvormen. Bij de kleinere aantallen studenten werden anamnese en onderzoek in het studentpatiëntcontact al zelden geobserveerd. ${ }^{3}$ Lukt het om dat te verbeteren als de grote aantallen studenten de co-assistentschap- pen bereiken? De commissie merkt op dat er in elk geval professionalisering op het gebied van onderwijs nodig is in de geaffilieerde ziekenhuizen. Een opvallende opmerking, omdat dit natuurlijk ook geldt voor de academische ziekenhuizen. De kwaliteit van de co-assistentschappen in de academische ziekenhuizen is tot nu toe niet beter, soms zelfs slechter, dan in geaffilieerde ziekenhuizen. Ik begrijp de opmerking dan ook alleen, als het academisch ziekenhuis wat betreft de co-assistentschappen door de commissie gezien wordt als een affiliatieziekenhuis. Ik weet echt niet of het zo bedoeld is, maar, als het zo bedoeld is, dan ben ik het met er volledig mee eens.

De commissie merkt op dat de rendementen heel verschillend zijn en dat is natuurlijk niet goed. Het hoogste rendement van de propedeuse na één jaar is $84 \%$ en het hoogste artsexamenrendement na zeven jaar is volgens de commissie 69\%. Uit oogpunt van doelmatigheid zijn zelfs de hoogste rendementen niet erg hoog. Ook financieel gezien is het niet handig om een laag rendement te hebben. Rendementen worden door vele factoren beïnvloed, die niet allemaal te veranderen zijn. Verbetermogelijkheden zijn: duidelijke examenreglementen zonder moeilijk te nemen hordes, niet te veel herkansingen, vroege opsporing van probleemstudenten, voorkomen van wachttijden door goede logistiek, proactieve studieadviseurs en mentoren. De commissie gebruikt voor de rendementen de kengetallen universitair onderwijs, die door de Vereniging van Universiteiten (VSNU) worden gegenereerd. De reden hiervoor was dat opleidingen hun rendementen verschillend beschreven. Een begrijpelijk, maar merkwaardig fenomeen. Het lijkt mij een uitdaging voor de Onderwijscommissie van het decanenoverleg om tot een eensluidende berekening te komen. In het eerder geciteerde 
artikel wordt opgemerkt dat de oprichting van onderwijs- of opleidingsinstituten er toe heeft geleid dat onderwijs veel professioneler wordt benaderd dan in het verleden. ${ }^{2}$ Als valkuil wordt gesignaleerd dat de bureaucratisering kan toeslaan en er te weinig ruimte is voor de echte 'opleiders'. Een andere valkuil is dat er minder ruimte is voor zelfkritiek en reflectie. Wat dat betreft is het voor de kwaliteit van de opleidingen van groot belang dat er kritische visitaties blijven. In de accreditatieprocessen krijgen de goede onderdelen van een opleiding veel aandacht. Voor de kwaliteit is dat zorgelijk. Dit kan leiden tot meer windowdressing, meer pr-activiteiten, minder zelfkritiek. In een goed systeem van interne kwaliteitszorg zijn deze gevaren ten dele op te vangen. Die systemen zijn nu, volgens de commissie, nog heel variabel en niet zo goed uitgekristalliseerd. Alleen 'intern' is dus niet zonder gevaar voor de kwaliteit. Zo constateerde de commissie dat veel stafleden niets wisten van de visitatie en de zelfstudie. De toekomst zal het ons leren, maar ik ben voor een combinatie van interne en externe kwaliteitszorg, dus ook voor kritische, lastige externe commissies. De commissie heeft haar oordeel deze keer ook in cijfers uitgedrukt. Hoewel door de decanen onderling was afgesproken dat de cijfers niet gehanteerd zouden worden, heeft de 'beste' faculteit dat wel gedaan. De cijfermatige beoordeling is over het algemeen positief. Op de oordelen over individuele faculteiten wordt hier niet ingegaan. Op zoek naar algemene verbeterpunten is in tabel 1 een lijst opgesteld waarbij als 'streng' criterium is gehanteerd dat vijf

Tabel 1. Onderdelen waarop 5 of meer van de 8 faculteiten minder dan goed (3), dus voldoende (2) of onvoldoende (1) scoorden.

\begin{tabular}{ll}
\hline $\begin{array}{l}\text { Missie, doelstellingen en eindtermen } \\
\text { van de opleiding }\end{array}$ & Operationalisering eindtermen. \\
$\begin{array}{ll}\text { Opbouw en inhoud van het } \\
\text { programma }\end{array}$ & $\begin{array}{l}\text { - Wetenschappelijke vorming (inclusief traject voor } \\
\text { excellente studenten en wetenschapsstage). } \\
\end{array}$ \\
& - Academische vorming (inclusief ethiek). \\
& - Krofessioneel gedrag (inclusief diversiteit). \\
Onderwijsleeromgeving & - Toetsing en beoordeling niet-klinisch deel. \\
& - Toetsing en beoordeling klinisch deel.
\end{tabular}

Studeerbaarheid

Rendementen

Effectiviteit van de organisatie, kwaliteiten van de staf

Faciliteiten en voorzieningen

Internationalisering en externe contacten

Interne kwaliteitszorg
Tentamenregelingen.

Artsexamenrendement.

- Structuur onderwijsorganisatie.

- Carrièrebeleid onderwijs.

- Contacten met affiliatieziekenhuizen.

- Personele inzet ten behoeve van onderwijs.

Faciliteiten klinisch deel van de opleiding.

- Internationaliseringsbeleid.

- Realisatie internationalisering.

- Functioneren systeem van interne kwaliteitszorg.

- Rol en positie van Opleidingscommissie.

- Rol en positie van Examencommissie. 
of meer van de acht faculteiten op dit onderdeel volgens de commissie minder dan goed (3), voldoende (2) of onvoldoende (1) scoorden.

Naast de onderwerpen die in het voorgaande al aan bod zijn geweest is er nog meer te verbeteren. De commissie maakt opmerkingen over de inhoud van de opleiding. Zij bepleit ondermeer meer aandacht voor wetenschappelijke en academische vorming. De meeste docenten zullen het hier wel mee eens zijn. In de onderwijspraktijk is het echter niet altijd eenvoudig om alle inhoud goed in het curriculum te krijgen en dan ook nog voldoende aandacht te besteden aan wetenschappelijke en academische vorming. Persoonlijk betwijfel ik of het hele Raamplan wel in het curriculum past. De eisen die beschreven worden passen beter bij een arts-assistent met één of twee jaar ervaring in een grote algemene discipline dan bij een basisarts. De commissie merkt ook op dat 'toetsing en beoordeling' en 'internationalisering' beter konden.

Samenvattend, vind ik dat het lezen van het rapport van de commissie zeer de moeite waard is; de in verbetering geinteresseerde lezer vindt in het algemene gedeelte tal van nuttige aanbevelingen.

\section{Elsevier-enquête}

Sinds 1994 wordt jaarlijks de uitslag van de Elsevier-enquête gepubliceerd. Het beeld over de jaren (figuur 1) laat zien dat de kwaliteitsoordelen over de faculteiten steeds dichter bij elkaar komen te liggen. Dit beeld werd vorig jaar ook al beschreven. ${ }^{5}$ Het komt overeen met de eerder genoemde constatering van de commissie dat de kwaliteit van de faculteiten dichter bij elkaar komt. ${ }^{1}$ Spannend wordt of we dit kunnen volhouden met de grotere aantallen studenten. Op zoek naar algemene verbeteringen is nagegaan op welke onderdelen vijf of meer van de acht faculteiten een 7 of lager scoorden (tabel 2).

Eerder zijn er wel twijfels geuit over de betrouwbaarheid van de gegevens. ${ }^{6}$ Toch is het een fascinerende bevinding en tevens een argument voor de validiteit van de enquête dat een aantal verbetermogelijkheden uit de enquête overeenkomt met de bevindingen van de commissie.

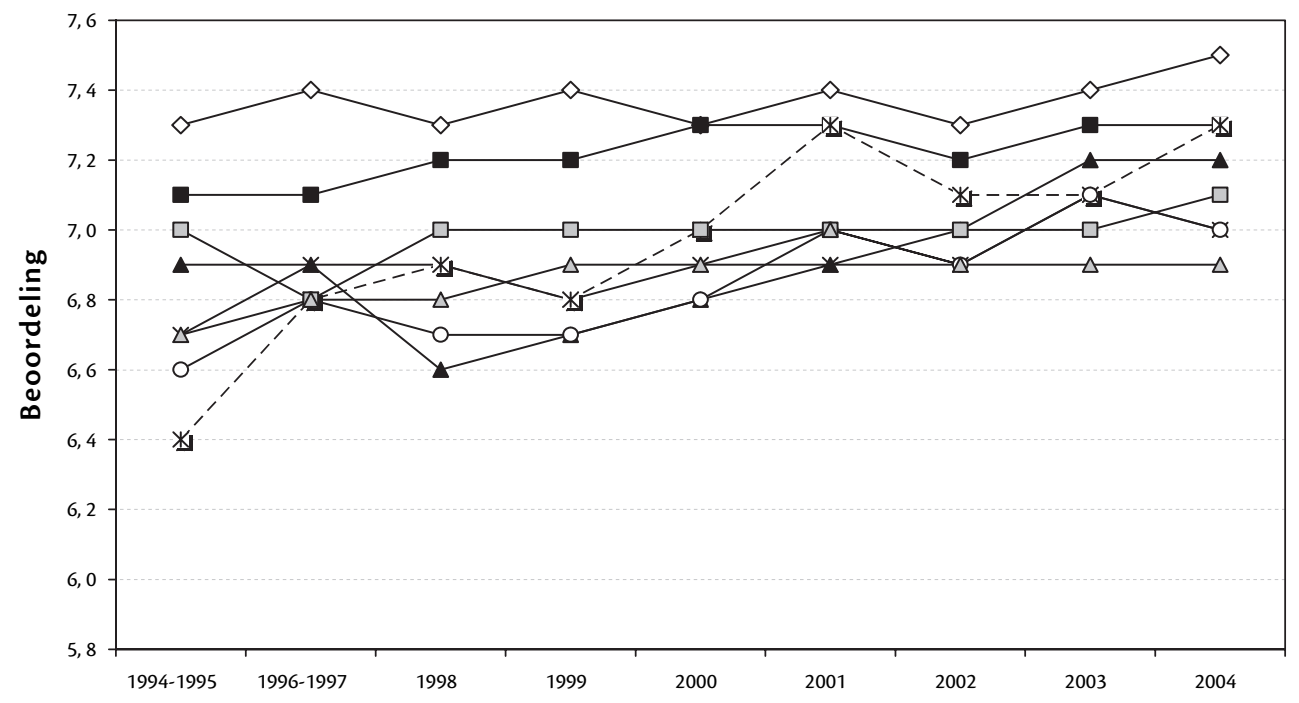

Figuur 1. Overzicht van de eindcijfers van 8 faculteiten op de Elsevier/NIPO-enquête van 1994-2004. 
Tabel 2. Onderdelen van de Elsevier/NIPOenquête waarop 5 of meer van de 8 faculteiten in 2004 een 7 of lager scoorden. 4

\begin{tabular}{ll}
\hline $\begin{array}{l}\text { Inrichting } \\
\text { opleiding }\end{array}$ & $\begin{array}{l}\text { Afspiegeling opleiding in } \\
\text { eerste jaar. } \\
\end{array}$ \\
& - Keuzemogelijkheden. \\
& het buitenland. \\
Docenten & - Bereikbaarheid. \\
& - Begeleiding bij opdrachten. \\
Onderwijs & Academische attitude en \\
& $\begin{array}{l}\text { vaardigheden. } \\
\text { Schriftelijke vaardigheden. }\end{array}$ \\
Organisatie \& & - Uitslag binnen termijn. \\
communicatie & - Communicatie met student.
\end{tabular}

\section{Het NVMO-congres}

In 2004 is het veertiende NVMO-congres gehouden. Het was een bijzonder congres, omdat er nauw is samengewerkt met het Centraal College Medische Specialismen (CCMS). Het resultaat was zeer positief. Een aantal workshops voor de vervolgopleidingen trok veel aandacht van opleiders. Deze samenwerking wordt door het NVMO-bestuur sterk ondersteund. In het kader van het opleidingscontinuüm en de veranderingen in de vervolgopleidingen levert deze samenwerking veel meerwaarde op voor de kwaliteit van het onderwijs.

In tabel 3 is een overzicht gegeven van de verschillende presentatievormen op het congres. Het aantal workshops neemt duidelijk toe. Deze verschuiving past goed bij de noodzaak tot professionalisering zowel voor de basisopleiding als voor de vervolgopleidingen. Het aantal papers neemt duidelijk af. Ongetwijfeld heeft de strengere selectie hiermee te maken. De ontwikkelde reviewprocedure voor abstracts (38 reviewers) leidt onmiskenbaar tot een verhoging van de kwaliteit van de abstracts. De procedure is gericht op het verbeteren van de abstracts en de indieners krijgen concrete adviezen om hun abstract te veranderen. Uiteraard leidt beoordelen ook tot beoordelingsproblemen en teleurgestelde indieners. Persoonlijk vind ik dat de procedure nog wel strenger mag. In een aantal abstracts wordt wel heel weinig of zelfs helemaal niets vermeld over de resultaten en ik zou zo'n abstract dus niet kunnen beoordelen. Wat echt niet kan, zijn zinnen als: "Ten tijde van het NVMO-congres zullen wij de bevindingen en evaluaties presenteren ..."; "Resultaten van de pilotstudy worden verwacht ..."; "De bevindingen worden gerapporteerd ..."; "Definitieve resultaten zijn ter congres beschikbaar", et cetera. Kortom, ik vind dat dergelijke abstracts niet meer geaccepteerd mogen worden. Dat is even wennen voor de indieners. Maar het is eigenlijk alleen een jaartje uitstel. Als er resultaten zijn tijdens het congres, kan een compleet abstract ingediend worden voor het volgende congres. En dan kan de auteur natuurlijk ook alvast beginnen met een artikel. Want het aantal mensen dat op een zo vol congres kennis kan nemen van een presentatie is beperkt door de vele parallelle activiteiten. Dus om de resultaten van onderzoek te kunnen delen met anderen, zodat meer mensen er wat aan hebben, moet het opgeschreven worden.

Tabel 3. Presentatievormen op het NVMO-congres van 2002 tot en met 2004.

\begin{tabular}{lccc}
\hline Presentatievorm & 2002 & $\mathbf{2 0 0 3}$ & $\mathbf{2 0 0 4}$ \\
\hline Papers & 65 & 53 & 43 \\
ICT & - & 9 & 10 \\
Posters & 18 & 31 & 29 \\
$2-2-8$ & 14 & 10 & 8 \\
Ronde tafel & 8 & 10 & 13 \\
Workshops & 5 & 7 & 19 \\
Totaal & 110 & 120 & 122 \\
\hline
\end{tabular}




\section{Hoe staan we er internationaal voor?}

Op de internationale medisch-onderwijscongressen is de Nederlandse inbreng relatief groot. Dat is eigenlijk al een aantal jaren zo. Er is de afgelopen jaren een toename van presentaties van verschillende Nederlandse faculteiten op internationale congressen te zien. Deze ontwikkeling is volledig terecht, want wat er in de verschillende curricula in Nederland gebeurt, is de moeite waard. Ook om het internationaal uit te dragen. Er wordt intussen ook meer internationaal gepubliceerd door verschillende faculteiten. Om dit enigszins te objectiveren is een vergelijking over 2004 gemaakt met de gegevens van Tutarel over 1995-2000 en gegevens van 2002-2003.5 Tutarel onderzocht wat de herkomst was van de eerste auteur van artikelen in Academic Medicine en Medical Education in de periode 1995-2000. ${ }^{7}$ De analyse over 2004 is beperkt tot Medical Education en, net als in het artikel van Tutarel, is er alleen naar de eerste auteur gekeken. Redactionele commentaren, ingezonden brieven et cetera zijn niet meegeteld. In tabel 4 is het percentage artikelen uit verschillende landen over de genoemde periodes weergegeven. In 1995-2000 stond Nederland op de vijfde plaats, in 2002-2003 op de vierde plaats en in 2004 op de derde plaats. Een prestatie waar we trots op mogen zijn. Zeker als meegeteld wordt dat het steeds moeilijker wordt om in Medical Education te publiceren, zoals
John Bligh - de hoofdredacteur - op het congres uitlegde. In absolute aantallen ging het in 1995-2000 om vijf artikelen per jaar. In 2002 en 2003 om negen artikelen per jaar en in 2004 om achttien artikelen per jaar.

\section{Hoe verder?}

De faculteiten/UMCs hebben concrete adviezen van de Visitatiecommissie gekregen om de kwaliteit verder te verbeteren. ${ }^{1}$ Of het gebeurt en of het lukt, zal moeten blijken. De zorg van de commissie of alle onderwijsverbeteringen van de afgelopen jaren in stand gehouden kunnen worden met de grotere aantallen studenten is mijns inziens volledig terecht. Bestuurders staan voor veel uitdagingen en daarin is het 'echte' belang van het onderwijs niet altijd duidelijk. Het onderscheid dat voor de curricula gemaakt wordt tussen 'curriculum op papier', 'curriculum in actie' en de 'outcome' geldt natuurlijk ook voor bestuurlijke processen. Ik hoop dat we kritisch genoeg kunnen en mogen blijven om de gevolgen van alle ontwikkelingen in de onderwijspraktijk te toetsen. Ik hoop ook dat we in dit alles kritisch getoetst blijven worden door lastige externe visitatiecommissies. Alleen vertrouwen op interne kwaliteitszorg lijkt mij nog een 'brug te ver', daarvoor zijn de belangen te groot en is het 'kritisch' vermogen te gering.

Het gegeven dat meer faculteiten tijd en energie gaan besteden aan onderzoek van

Tabel 4. Percentage artikelen uit verschillende landen in Medical Education in verschillende perioden.

\begin{tabular}{lccc}
\hline & $1995-2000$ & $2002-2003$ & 2004 \\
\hline Verenigd Koninkrijk & $42.6 \%$ & $44.8 \%$ & $32.3 \%$ \\
Australië & $11.7 \%$ & $8.4 \%$ & $9.4 \%$ \\
Verenigde Staten & $10.5 \%$ & $15.2 \%$ & $17.3 \%$ \\
Canada & $5.8 \%$ & $6.4 \%$ & $8.6 \%$ \\
Nederland & $3.5 \%$ & $7.2 \%$ & $14.1 \%$ \\
Overig & $25.9 \%$ & $18.0 \%$ & $18.1 \%$ \\
\hline
\end{tabular}


onderwijs is positief en geeft hoop voor de toekomst van het medisch onderwijs. $\mathrm{Na}$ al het goede ontwikkelwerk dat er op veel plaatsen is gedaan, is het nu echt tijd voor meer onderzoek naar de echte effecten.

\section{Literatuur}

1. Visitatiecommissie Geneeskunde. Onderwijsvisitatie Geneeskunde 2003. Utrecht: Stichting Quality Assurance Netherlands Universities (QANU); 2004.

2. Huisjes HJ, Denekens J. De onderwijsvisitatie geneeskunde 2003. Tijdschrift voor Medisch Onderwijs 2004;23(3):127-32.

3. Vleuten CPM van der, Scherpbier AJJA, Dolmans DHJM, Schuwirth LWT, Verwijnen GM, Wolfhagen HAP. Clerkship assessment assessed. Med Teach 2000;22(6):592-600.

4. WO: Gezondheid. Studentenonderzoek. Elsevier: Elsevier Thema; 2004. p. 80-2.

5. Scherpbier AJJA. Het medisch onderwijs en het NVMO-congres. Waar staan we en hoe moet het verder? Tijdschrift voor Medisch Onderwijs 2004;23(4):172-7.
6. Scherpbier AJJA, Zwierstra RP. De kwaliteit van de medische opleidingen getoetst? Tijdschrift voor Medisch Onderwijs 2002;21(1):2-8.

7. Tutarel O. Geographical distribution of publications in the field of medical education. BMC Med Educ 2002;2:3. Beschikbaar op: http://www. biomedcentral.com/1472-6920/2/3.

\section{De auteurs:}

Prof. dr. A.J.J.A. Scherpbier is hoogleraar en wetenschappelijk directeur van het Onderwijsinstituut van de Faculteit der Geneeskunde, Universiteit Maastricht. Tevens is hij voorzitter van de NVMO.

Correspondentieadres:

Prof. dr. A.J.J.A. Scherpbier, Onderwijsinstituut Geneeskunde, Postbus 616, 6200 MD Maastricht, tel.: 043-3881400, fax: 043-3884165, a.scherpbier@oifdg. unimaas.nl.

\section{Summary}

Reflections on key issues in medical education were inspired by the 2004 educational audit and NVMO conference. Educational audit: Medical schools differ less. The annual Elsevier survey confirms this. Effects of academic medical centres and curriculum revisions remain to be ascertained. More students call for more qualified teachers to ensure educational quality, particularly in patient-based training, where observation of student-patient contacts remains rare. Output may benefit from clear examination regulations, detection of problem students and prevention of waiting times. The establishment of education institutes has induced a more professional approach to education. Pitfalls are: more bureaucracy, insufficient attention for the real 'educators' and insufficient self-criticism and reflection. This underlines the need for rigid external audits, particularly given the suboptimal internal quality systems. Scientific and academic education, assessment and evaluation, and internationalisation need attention also.

NVMO-conference: Collaboration with the Central College of Medical Specialties has high priority for NVMO. Professional development of educators is emphasised by the increasing number of workshops. Selection criteria for papers are stricter to improve the quality of presentations. The writing of papers is encouraged, because papers reach a wider audience than conference presentations. Good news is that the Netherlands has risen from fifth to third place among countries with publications in international medical education journals.

Future developments: Educational improvements require critical attitudes of medical schools and administrators. Internal and external measures for quality improvement, including critical, external audit committees can support this. After concentrating on educational development - research should now focus on outcomes. (Scherpbier AJJA. Reflections on education and the 2004 NVMO conference. Dutch Journal of Medical Education 2005;24(5):197-203.) 